\title{
The Impact of Financial Industry on Energy Development Based on VAR Model
}

\author{
Sun Dong \\ School of Economics and Management, North China \\ Electric Power University \\ Beijing, China \\ e-mail:sundong@ncepu.edu.cn
}

\author{
Zhao Haoran* \\ School of Economics and Management, North China \\ Electric Power University \\ Beijing, China \\ e-mail:haoranzhao0118@163.com \\ * Corresponding Author
}

\begin{abstract}
With the development of industrialization, the world's energy supply and demand contradictions become increasingly sharp, a difficult problem of optimizing energy industry structure and reducing external dependence need to be solved by the support of finance. Therefore, on the basis of analyzing the research results of the domestic and foreign scholars in the field of energy finance, the total energy production, energy industry processing conversion efficiency, total investment of fixed assets of energy industry and the use of RMB credit funds in financial institutions/GDP of 1991-2012 are used to establish co-integration model and the impulse response function to measure the degree of the influence of the development of finance on the development of energy industry. Finally, concluding that the financial industry has a weak effect on the development of energy industry and putting forward some related suggestions through the analysis of empirical results to make the financial industry better serve the development of energy industry.
\end{abstract}

Keywords-energy-finance; co-integration; impulse response function; energy financialization

\section{INTRODUCTION}

Energy is the basis of social development. With the continuous deepening of the world industrialization process, since 1992, energy consumption is greater than the energy output, and the former is 1091.6 million tons of standard coal, while the latter is 1072.6 million tons of standard coal, which means that the contradiction of the energy supply and demand is increasingly prominent. At present, according to the actual situation, the governments of various countries have implemented some policies to stimulate the development of clean energy, develop the use of renewable resources and optimize the structure of the energy industry, which mainly requires financial support.

A.Derrick[1] and Painuly[2] thought that the main obstacle that spread the clean energy system in less developed countries is the lack of appropriate funds system, and proposed to establish a new energy system to promote the extensive use of renewable energy . Dalia[3] has deeply discussed the fact that some countries of the European Union system used the EU structural funds to promote their energy industry progress, and put forward some constructive suggestions on how to use the fund rationally to develop domestic energy industry. Huang[4] pointed out that the expansion of financial scale can promote the increase of output value, and the contribution rate of different financing structure to the output growth and energy consumption is quite different, but the opening and use efficiency of financing is declining. Li[5] used VAR method to quantify the impact of coal industry financial security indicators and established a VEC model to analyze the long-term and short-term economic relations of the impact indicators and the financial security of the coal industry. Huang[6] put forward lots of ways to raise funds to meet the development of urban and rural green resources through the comparison between China and India in the development of financial support for urban and rural areas of green resources, such as, financing through renewable energy service companies, fixed asset financing, joint ventures, venture capital investment and government subsidies. On the basis of literature analysis, the quantitative research is less than qualitative literature. Therefore, this paper uses econometric method to study the promotion effect of finance on energy industry and the mutual impact effect of finance and energy industry.

\section{Methodology}

\section{A. Stationary test of the time series}

It is assumed that a time series is generated by a stochastic process, which means every value of time series $\left\{X_{t}\right\}(t=1,2, \cdots)$ is obtained from a probability distribution, if $X_{t}$ satisfy the following conditions:

1) $E\left(X_{t}\right)=\mu$ is a constant which has nothing to do with time t;

2) $\operatorname{Var}\left(X_{t}\right)=\sigma^{2}$ is a constant which has nothing to do with time t;

3) $\operatorname{Cov}\left(X_{t}, X_{t+k}\right)=\gamma_{k}$ is only related to the interval $\mathrm{k}$. Therefore, the random time series is stationary and the stochastic process is a stationary random process. If the non - stationary time series is used to carry out regression analysis, the pseudo regression problem will appear, so before establish the model, we must test the stationary of the sequence. The unit root ADF test is the commonly used test which establishes a model as below:

$$
\Delta X_{t}=\alpha+\beta t+\delta X_{t-1}+\sum_{i=1}^{p} \theta_{i} \Delta X_{i-t}+\varepsilon_{t}
$$


where $\alpha$ is a constant, $\mathrm{t}$ is a trend term, $\mathrm{p}$ is the optimal lag order, and $\varepsilon_{t}$ is the random error term. For a given level of significance, if the ADF test value is less than the critical value, the time series is stationary.

Johansen co-integration test

Johansen co-integration test constructs two statistics test, which is 'the characteristic value trajectory test' and 'the maximum characteristic value test'.

First, the characteristic equation can be set as

$$
\left|\lambda R_{11}-R_{10} R_{00}^{-1} R_{01}\right|=0
$$

where $R_{00}=T^{-1} S_{0} S_{0}^{\prime}, R_{01}=T^{-1} S_{0} S_{1}^{\prime}, R_{10}=T^{-1} S_{1} S_{0}^{\prime}, R_{11}=T^{-1} S_{1} S_{1}^{\prime}$, $S_{0}$ is a $\mathrm{k}^{*} \mathrm{~T}$ residual matrix obtained by using OLS to evaluate the equations of $\Delta y_{t}=\sum_{j=1}^{p} \Gamma_{j} \Delta y_{t-j}+B x_{t}+\varepsilon_{t}$, and $S_{1}$ is a $\mathrm{k} * \mathrm{~T}$ residual matrix obtained by using OLS to evaluate the equations of $\Delta y_{t-1}=\sum_{j=1}^{p} \Gamma_{j} \Delta y_{t-j}+B x_{t}+\varepsilon_{t}$.

Estimate the characteristic equation of descending eigenvalues, and the corresponding feature vector is the co integration vector $\beta$.

Using 'characteristic value trajectory test' to test trajectory statistic:

$$
\eta(k-r)=-T \sum_{i=r+1}^{k} \ln \left(1-\lambda_{i}\right)
$$

When $\eta(k)$ is not significant, then we should accept the original hypothesis $H_{0}(r=0)$, and there is no cointegration vector. Otherwise, we should accept the alternative hypothesis $H_{1}(r>0)$, and we should carry out further test for the significance of $\eta(k-1)$, until the first insignificant $\eta(k-r)$ is appear, which indicates there are $\mathrm{r}$ co-integration vector.

Using 'maximum characteristic value test' to test maximum eigenvalue statistic:

$$
\xi(r)=-T \ln \left(1-\lambda_{r+1}\right)
$$

When $\zeta(0)$ is not significant, then we should accept the original hypothesis $H_{0}(r=0)$, and there is no cointegration vector. Otherwise, we should accept the alternative hypothesis $H_{1}(r>0)$, and we should carry out further test for the significance of $\zeta(1)$, until the first insignificant $\zeta(r)$ is appear, which indicates there are $\mathrm{r}$ co-integration vector.

\section{EMPIRICAL ANALYSIS OF FINANCIAL IMPACT ON ENERGY INDUSTRY DEVELOPMENT}

This part mainly uses VAR model, co-integration theory and impulse response function to study the impact of finance on the development of the energy industry.

\section{A. Data sources and processing}

This paper selects the data of 22 years from 1991 to 2012 using the Eviews 6.0 software to expand the empirical analysis, and the indicators and processing method are shown in Table I. Specifically, energy conversion efficiency is used to represent the level of energy conversion device and production technology, the use of RMB credit funds in financial institutions/GDP is on behalf of the financial development, and total investment of fixed assets of energy industry is also used in the model as it has great impact on the energy industry.

TABLE I. DATA PROCESSING AND PRESENTATION

\begin{tabular}{l|l|l}
\hline \multicolumn{1}{c|}{ Indicators } & Presentation & Processing method \\
\hline Total energy production & EP & Compute logarithm \\
\hline $\begin{array}{l}\text { Energy industry processing } \\
\text { conversion efficiency }\end{array}$ & EF & $\begin{array}{l}\text { Compute logarithm } \\
\text { after multiply } 100\end{array}$ \\
\hline $\begin{array}{l}\text { Total investment of fixed assets } \\
\text { of energy industry }\end{array}$ & GDI & Compute logarithm \\
\hline $\begin{array}{l}\text { The use of RMB credit funds in } \\
\text { financial institutions/GDP }\end{array}$ & FIN & $\begin{array}{l}\text { Compute logarithm } \\
\text { after multiply } 100\end{array}$ \\
\hline
\end{tabular}

\section{B. Empirical analysis process}

\section{Data stationary test}

Generally, when the time series is not stable, the regression analysis of the econometric model is likely to be a 'pseudo regression' phenomenon. Therefore, the ADF unit root test is employed to determine the stability of the sequence and the order of the single integer. The ADF test results of the variables are shown in Table II.

TABLE II. THE ADF TEST RESULTS OF THE VARIABLES.

\begin{tabular}{c|c|c|c|c}
\hline Sequence & $\begin{array}{c}\text { Test form } \\
(\mathrm{C}, \mathrm{T}, \mathrm{K})\end{array}$ & ADF test value & P value & Conclusion \\
\hline $\ln E P$ & $\mathrm{~N}, \mathrm{~N}, 1$ & 0.256316 & 0.9156 & Unstable \\
\hline$\Delta \ln E P$ & $\mathrm{~N}, \mathrm{~N}, 0$ & -3.912448 & 0.0085 & Stable \\
\hline $\ln E F$ & $\mathrm{~N}, \mathrm{~N}, 0$ & -2.068424 & 0.2581 & Unstable \\
\hline$\Delta \ln E F$ & $\mathrm{~N}, \mathrm{~N}, 0$ & -7.034588 & 0.0000 & Stable \\
\hline $\ln G D I$ & $\mathrm{~N}, \mathrm{~N}, 2$ & 0.308813 & 0.9722 & Unstable \\
\hline$\Delta \ln G D I$ & $\mathrm{~N}, \mathrm{~N}, 1$ & -2.665819 & 0.0981 & Stable \\
\hline $\ln$ FIN & $\mathrm{N}, \mathrm{N}, 0$ & -0.446011 & 0.8836 & Unstable \\
\hline$\Delta \ln$ FIN & $\mathrm{N}, \mathrm{N}, 1$ & -3.762846 & 0.0115 & Stable \\
\hline
\end{tabular}

The unit root test results show that in the $10 \%$ significance level $\ln E P, \ln E F, \ln G D I, \ln F I N$ are nonstationary sequence and single integer, which means the co-integration test can be carried out.

Co-integration test of the energy industry and finance

The co-integration test results are shown in Table III and Table IV.

TABLE III. JJ TEST RESULTS (TRACE TEST)

\begin{tabular}{c|c|c|c|c}
\hline Null hypothesis & $\begin{array}{c}\text { Characteristi } \\
\text { c value }\end{array}$ & $\begin{array}{c}\text { Trace } \\
\text { statistics }\end{array}$ & $\begin{array}{c}\text { 0.05critical } \\
\text { value }\end{array}$ & $\begin{array}{c}\text { Confidence } \\
\text { probability }\end{array}$ \\
\hline None & 0.975052 & 146.6534 & 47.85613 & 0.0000 \\
\hline At most one & 0.947239 & 76.41045 & 29.79707 & 0.0000 \\
\hline At most two & 0.621210 & 20.51270 & 15.49471 & 0.0080 \\
\hline At most three & 0.103129 & 2.068014 & 3.841466 & 0.1504 \\
\hline \multicolumn{5}{|r}{}
\end{tabular}


TABLE IV. JJ TEST RESULTS (MAXIMUM CHARACTERISTIC ROOT TEST)

\begin{tabular}{c|c|c|c|c}
\hline Null hypothesis & $\begin{array}{c}\text { Characteristic } \\
\text { value }\end{array}$ & $\begin{array}{c}\text { Trace } \\
\text { statistics }\end{array}$ & $\begin{array}{c}\text { 0.05critical } \\
\text { value }\end{array}$ & $\begin{array}{c}\text { Confidence } \\
\text { probability }\end{array}$ \\
\hline None & 0.975052 & 70.24298 & 27.58434 & 0.0000 \\
\hline At most one & 0.947239 & 55.89776 & 21.13162 & 0.0000 \\
\hline At most two & 0.621210 & 18.44468 & 14.26460 & 0.0103 \\
\hline At most three & 0.103129 & 2.068014 & 3.841466 & 0.1504 \\
\hline
\end{tabular}

The co-integration test results show that the total energy production, energy industry processing conversion efficiency, total investment of fixed assets of energy industry and the use of RMB credit funds in financial institutions/GDP of 1991-2012 maintain long-term equilibrium. The co-integration equation can be expressed as:

$$
\ln E P=0.46 \ln E F+0.61 \ln G D I+0.47 \ln F I N
$$

Analysis of the dynamic impact of Finance on the development of energy industry

To explore the impact between finance and energy industry, this part use impulse response function to analyze the shock effect between them, and the results are shown

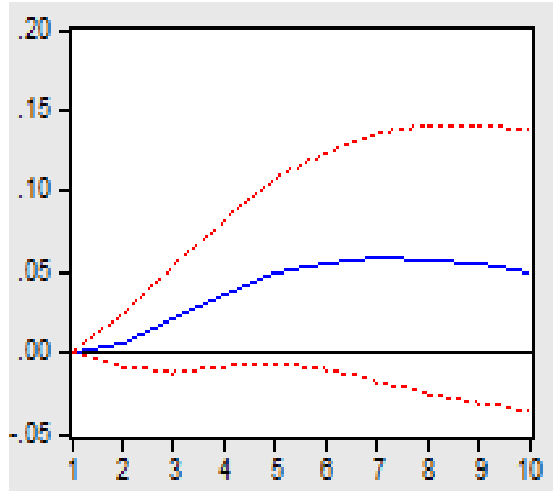

Figure 1. The impact of finance on the development of energy industry.

\section{CONCLUSIONS AND RECOMMENDATIONS}

During the whole sample period, the financial industry has an important influence on the promotion of energy industry, but the effect is relatively weak. The result of impulse response function analysis shows that the development of energy industry has a positive effect on finance, and the development of the finance has a positive effect on energy industry. Therefore, promoting the development of the financial industry will also contribute to the energy industry, and the development of the energy industry will also be conducive to the development of finance.

To make the finance conduce to the development of energy industry to a great extent, the development level of the financial market should be enhanced, and the resource allocation behavior of financial institutions should be standardized. Therefore, some suggestions are given as follows.

(1)Improving the level of energy finance market development. On the one hand, we can broaden the financing channels for energy companies. For the listed in Fig. 1 and Fig .2. According to the impulse response function, the dynamic response path of the mutual impact between the total energy production and the use of RMB credit funds in financial institutions/GDP can be drawn. The horizontal axis is the response time of the impulse response function and the longitudinal coordinate is the response of a standard differential impact to the disturbance term. The solid line shows the response curve with two confidence value, the dotted line represents two times of standard deviation. As can be seen from Fig .1.the impact of the financial industry development on the energy industry has always been positive, from the beginning of the first, the impact increased gradually, and reaching the highest point of 0.058 at seventh stage, and then the impact declined, but still maintained positive value. It implied that the development of the financial industry can promote the development of the energy industry. From Fig .2. we can draw the conclusion that the impact of energy industry on the development of the financial industry has always been positive, from the beginning of the first, the impact increased gradually, reaching the highest point of 0.038 at fourth stage, then the impact of the impact gradually reduced, but the value of the eighth phase began to rise. It indicated that the development of supporting energy industry will promote the progress of the financial industry.

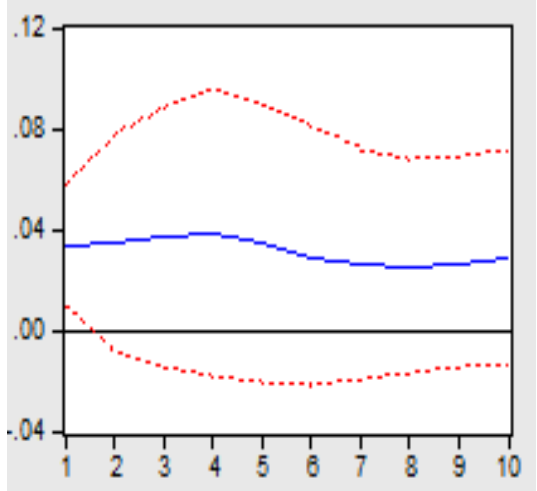

Figure 2. The impact of energy industry on the development of finance.

energy companies, we should continue to expand the scale of its listing, and improve the proportion of equity financing. For the non listed energy companies, we should focus on promoting quality assets listed and promote direct financing. Secondly, we should support energy companies to issue short-term and long-term bonds and raise the proportion of debt financing. On the other hand, we should improve the level of financial innovation. Energy related products and services should be introduced to domestic market, such as coal futures, energy efficiency company and things like that. Simultaneously, we should also learn from foreign advanced experience, and gradually increase the power, coal, biomass and solar and other futures contracts to diversify the types of financial derivatives of energy.

(2) Regulating financial resources allocation behavior of financial institutions. On the one hand, we should control the short-sighted behavior of financial institutions. On the other hand, the financial and environmental risks caused by the convergence of credit should be monitored. The corresponding monitoring and analysis and early warning mechanism should be established and improved. 
We should also improve the relevant policies and regulations to prevent the fluctuations of energy prices and avoid financial risks.

\section{REFERENCES}

[1] A. Derrick. Financing mechanisms for renewable energy[J]. Renewable Energy,1998,(15):211-214.

[2] J.P Painuly,H Park,M.-K Lee,J Noh. Promoting energy efficiency financing and ESCOs in developing countries: mechanisms and barriers[J]. Journal of Cleaner Production,2002,(11):659-665.

[3] D Streimikiene, V Klevas,J Bubeliene. Use of EU structural funds for sustainable energy development in new EU member states[J]. Renewable and Sustainable Energy Reviews,2007,(11):1167-1187.

[4] Huang He, Zhang Jian-hua. Energy Industry Development and financial support: a panel data analysis [J]. Journal of Guangdong University of Finance, Vol. 2 5,No. 4,2010 (7) ,89-99
[5] Li Kaifeng, Liu Chuanzhe. Analysis of the factors affecting the financial security of the coal industry in China based on VaR[J]. China Safety Science Journal,2010,07:134-140.

[6] Huang Liming. Financing rural renewable energy: a comparison between China and India[J]. Renewable and Sustainable Energy Reviews,2008,(3):21-28.

[7] Zheng Yanyan. Impulse response function theory and its application in macro economy[D]. Nankai University,2010

[8] The task group of the International Institute of finance, Bank of China, Huang Zhiqiang. Energy finance strategy in China under the global energy pattern[J]. International Finance Research, 2012,04:32-41.

[9] He Lingyun, Xue Yonggang. Energy finance connotation and structure from the perspective of industrial symbiosis[J]. Productivity research, 2010,12:224-225+272.

[10] Wang Lei. The problems and countermeasures of the development of China's energy financial market[N]. China Energy News,201201-09024 